\title{
Efficacy of pregabalin as adjuvant analgesia to diclofenac sodium in laparotomies for benign gynaecological diseases: A randomized controlled trial
}

\section{Original Article}

\author{
Ahmed Adel Tharwat, Reda Mokhtar Kamal Ghanem, Amany Esmat Osman \\ El-Habian
}

Department of Obstetrics and Gynecology, Faculty of Medicine, Ain Shams University, Egypt

\begin{abstract}
Background: Abdominal surgeries are considered one of the most painful among all types of surgeries. About $70 \%$ of patients who had abdominal surgeries suffered from severe pain in the postoperative period especially the gynaecological one. This pain as well as fatigue is the two key causes of prolonged convalescence following abdominal surgery. In order to relieve pain and fatigue, a current predominant approach of multimodal postoperative analgesia is used, mostly based on a combination of opioids, non-steroidal anti-inflammatory drugs (NSAIDs), paracetamol and perioperative administration of local anesthetics. Each of these different approaches has its own set of complications.

Objective: The current study aimed to assess the efficacy of oral pregabalin $150 \mathrm{mg}$ as adjuvant analgesic to i.v diclofenac sodium $75 \mathrm{mg}$.

Patients and Methods: A randomized controlled trial was done on female patients who had laparotomies for benign gynaecological diseases in Ain Shams University Maternity Hospital during duration of nine months. The trial included one hundred and sixteen patients, divided into two equal groups. The first group (group A) received oral pregabalin 150 $\mathrm{mg}$ with i.v diclofenac sodium $75 \mathrm{mg}$ one hour before operation and 12 hours after operation and was repeated every 12 hours for the first 24 hours and/or in demand. The second group (group B) received intravenous diclofenac sodium $75 \mathrm{mg}$ 12 hours after operation and was repeated every 12 hours for the first 24 hours and/or in demand. The primary objective is measuring pain six hours postoperative and every one hour by using VAS-100 score, the secondary objective is measuring patient ambulation and audible intestinal sounds 6 hours postoperative.

Results: Pain perception was significantly lower among group A than group B. As on VAS study group record of 20-10, control group record 45-30. Analgesia-free time was significantly lower among study than among control by 2 hours. Side effects were more frequent among study than among control group, but the differences were significant only in somnolence. This study showed also a significant early post-operative mobilisation in those who took oral pregabalin $150 \mathrm{mg}$ in comparison to those who took i.v diclofenac sodium $100 \mathrm{mg}$ that is attributed to decrease pain perception. It revealed also no significant difference between both groups regarding the intestinal activity.

Conclusion: Administration of oral pregabalin $150 \mathrm{mg}$ preoperatively reduce post-operative pain following abdominal gynecological operation, decrease the need of usage of post-operative narcotic analgesic, early patient mobilization that finally improve the surgical outcome and the patient quality of life.
\end{abstract}

Key Words: Diclofenac sodium, gynaecological diseases, pregabalin

Received: 11 September 2018, Accepted: 7 October 2018

Corresponding Author: Amany Esmat Osman El-Habian, MSc., Department of Obstetrics and Gynecology, Ain-Shams University, Tel.: 01018848219, E-mail: amanyesmatosman@gmail.com

ISSN: 2090-7265, May 2019, Vol.9, No. 2

\section{INTRODUCTION}

Abdominal surgeries tend to be the most painful among all types of surgeries and $70 \%$ of the patients suffer from severe pain in the postoperative period ${ }^{[1]}$. Post-operative pain and fatigue are two of the key causes of prolonged convalescence following abdominal surgery ${ }^{[2]}$. The current predominant approach of multimodal postoperative analgesia is mostly based on a combination of opioids, non-steroidal anti-inflammatory drugs (NSAIDs), paracetamol and perioperative administration of local anaesthetics. Each of these approaches comes with its own set of complications ${ }^{[3]}$.

The emerging concepts of pre-emptive analgesia, a drug that has analgesic properties, opioid sparing effects, which possibly reduces opioid tolerance, relieves anxiety and is not associated with adverse effects. Such 
one would be typical for the traditional analgesic and would be an attractive adjuvant for post-operative pain management ${ }^{[4]}$.

Non-steroidal anti-inflammatory drugs (NSAIDS) like diclofenac exert their action via inhibition of prostaglandin (PG) synthesis by inhibiting cyclooxygenase-1 (COX-1) and COX-2 enzymes with relative equipotency ${ }^{[5]}$. Previous studies have demonstrated the safety and efficacy of single- and multiple-dose of hydroxypropyl- $\beta$-cyclodextrin (HP $\beta C D$ )-diclofenac in postsurgical patients ${ }^{[6]}$. Moreover, in the management of mild to moderate pain and moderate to severe pain, alone or in combination with opioid analgesics ${ }^{[7]}$.

Pregabalin is an attractive adjuvant for perioperative analgesia in this regard, as it can be taken on an empty stomach and does not lead to gastrointestinal bleeding and is generally well-tolerated ${ }^{[8]}$. The administration of oral pregabalin preoperatively has been reported to reduce acute postoperative pain ${ }^{[9]}$ and to prolong the duration of anaesthesia produced by single-injection peripheral nerve blockade ${ }^{[10]}$. The efficacy of pregabalin in treating acute postsurgical pain has been demonstrated in numerous studies. A recent meta-analysis study suggested that pregabalin, at all doses and administration regimens, has opioid-sparing effects and reduces pain scores in the postsurgical setting ${ }^{[11]}$.

Pregabalin is a structural analogue of gamma amino butyric acid (GABA). It acts through presynaptic binding to the alpha-2-delta subunit of voltage-gated calcium channels that are widely present in both the spinal cord and the brain. Therefore, it modulates the release of many excitatory neurotransmitters, such as glutamate, norepinephrine, substance-P and calcitonin gene related peptide. It causes inhibitory modulation of overexcited neurons and restores them to a normal state. Centrally, pregabalin is able to decrease the hyperexcitability of the dorsal horn neurons that is caused by tissue damage ${ }^{[12]}$.

\section{AIM OF THE WORK}

The current study aimed to assess the efficacy of oral pregabalin $150 \mathrm{mg}$ as adjuvant analgesic to i.v diclofenac sodium $100 \mathrm{mg}$ since up to our knowledge no similar study had been done in Egypt.

\section{PATIENTS AND METHODS}

This is a randomized controlled trial which was performed at Ain-Shams University Maternity Hospital. It compared the pain relief effect of oral pregabalin combined with i.v. diclofenac sodium versus i.v. diclofenac sodium alone after benign gynecological laparotomies.
It included 116 patients to which 10 more were added to avoid the possibility of drop out in the original sample. All participants were randomly assigned to two equal groups (each include 58) using number sealed opaque envelopes stored in the physicians' office within each envelope a card indicating the words pregabalin and diclofenac sodium or the word diclofenac sodium.

The first group (A) : study group included one capsule of lyrolin, which contain $150 \mathrm{mg}$ pregabalin (El-Hekma pharmaceuticals, Egypt) and one ampule of voltarin which contain diclofenac sodium $75 \mathrm{mg}$ (Novartis pharmaceuticals, Egypt).

The second group (B) : control group included one ampule of voltarin which contain diclofenac sodium $75 \mathrm{mg}$.

Group sample size of 53 patients in each study group would achieve a power of $80 \%$ (type II error, 0.2 ) to

$$
\text { Cohen } f=\frac{\text { Standard deviation of group means }}{\text { Common standard deviation }}
$$

detect a statistically significant difference among the two groups as regards the main outcome measures (pain score, analgesic consumption and time to ambulation) for a medium effect size corresponding to an $\mathrm{f}$ coefficient of 0.25 using a two-sided F-test and the targeted test confidence set at a level of 95\% (type I error, 0.05). The effect size (f) is calculated as follows ${ }^{[13]}$ :

The targeted effect size of $d=0.5$ has been selected as it could be regarded as clinically relevant difference to seek in this exploratory study.

The study was approved by ethical committee of the Faculty of Medicine, Ain Shams University. All participants received a detailed explanation about the study design and had approved oral consent.

\section{Study design}

The study included inpatient with the following inclusion criteria:

-Age: 2070- years of age.

-BMI: $1828-\mathrm{kg} / \mathrm{m} 2$.

-Women candidate for surgical intervention via laparotomy for different gynecological pathologies with controlled medical comorbidity.

Patients were excluded from the study if they had one of the following:

-Suspected pregnancy

-Suspected malignancy 
-Suspected pelvic infection

-Dense pelvic adhesion

-Confirmed endometriosis

-Chronic liver disease

-Chronic renal disease

-Gastritis

-Peptic ulcer

-Hormonal treatment for the last 6 months

-Drugs as enzyme inducer "e.g: rifambicine, spironolactone, grisofulvin and barbiturates", steroids and immunosuppressive.

-Any contraindication to the pregabalin and diclofenac sodium.

-Patient's unwillingness to participate in the study.

\section{Methods:}

All women involved in this study were subjected to full history and clinical examination to eliminate those with exclusion criteria.

\section{History:}

A thorough history taking, with special emphasis on: -Patient age.

-Patient menstrual history.

-Parity and number of deliveries.

-Menopausal status and years after the menopause.

-Any symptoms donating; pregnancy, genital cancer, pelvic infection and pelvic adhesion.

-History of drug intake.

\section{Examination:}

1-General examination: for preoperative assessment.

2-Full abdominal examination: for assessment of gynecological diseases.

3-Full pelvic examination:

Inspection of vulva and vagina

-Examination of the cervix as regard position, consistency, mobility and any palpable swelling.

-Bimanual examination of the uterus for position, size symmetry and mobility.

-Examination of both adnexae and douglas pouch.

\section{Investigation:}

Routine preoperative investigation in addition to serum $\beta \mathrm{hCG}$ if pregnancy is suspected, $\mathrm{ABO}-$ RH grouping, CBC, PT, PTT, INR, AST-ALT, Urea, Creatinine, ECG (to patient above 40 years), and Echo (to patient above 50 years).

\section{Before operation:}

Before being admitted to the clinical study, all patients signed consent to participate after the nature and scope of the clinical study, usage of the drug and side effects of the drugs had been explained in an understandable form to her.
Women in group A were instructed to take their pregablin capsules one hour before initiation of anesthesia.

\section{After operation:}

The two groups took analgesia postoperative every 12 hours and/or on demand as follows:

Group (A): Took both oral pregabalin capsule and i.v. diclofenac sodium.

Group (B): Took i.v. diclofenac sodium alone.

The visual analogue scale was shown and explained to the patients for recording the degree of pain on the chart. The pain assessment was done every 12 hours by the visual analogue scale (VAS) to quantify pain felt by the patient after laparotomies over the first 24 hours.

Start hearing intestinal sound after the first 6 hours, if not heard then after the first 8 hour, if not heard then after the first 12 hour, finally using of rectal glycerine suppository for stimulating bowel movement.

\section{STATISTICAL ANALYSIS}

Data were analyzed using IBM $($ SPSS $($ Statistics version 22 (IBMC) Corp., Armonk, NY) and the following was done:

Qualitative data were presented as number and percentages while quantitative data were presented as mean, standard deviations and ranges. The comparison between two groups with qualitative data were done using Chi-square test and/or Fisher exact test was used instead of Chi-square test when the expected count in any cell was found less than 5 . The comparison between two independent groups with quantitative data and parametric distribution was done by using Independent t-test. The confidence interval was set to $95 \%$ and the margin of error accepted was set to $5 \%$.

\section{RESULTS}

Table 1 shows the demographic characteristics among the studied groups. No significant difference between the studied groups regarding demographic characteristics was found. Table 2 shows that pain perception was significantly lower among study group than the control group. As on VAS study group record of 20-10, control group record 45-30. Table 3 shows that analgesia-free time was significantly lower among study than among control by 2 hours. Table 4 shows that locomotor activity start was significantly earlier among study than among control by 2 hours. Table $\mathbf{5}$ shows that intestinal activity start was significantly earlier among study than among control by 1 hour. Table 6 shows that side effects were more frequent among study than among control group, but the differences were significant only in somolence. 
Table 1: Demographic characteristics among the studied groups

\begin{tabular}{|c|c|c|c|c|}
\hline Items & Measure & $\begin{array}{c}\text { Study } \\
(\mathrm{N}=58)\end{array}$ & $\begin{array}{l}\text { Control } \\
(\mathrm{N}=58)\end{array}$ & $\mathrm{P}$ \\
\hline \multirow{2}{*}{$\begin{array}{c}\text { Age } \\
\text { (years) }\end{array}$} & Mean $\pm \mathrm{SD}$ & $41.8 \pm 6.8$ & $42.3 \pm 7.6$ & \multirow{2}{*}{$\wedge 0.681$} \\
\hline & Range & $22.0-54.0$ & $28.0-59.0$ & \\
\hline \multirow{2}{*}{$\begin{array}{c}\text { BMI } \\
(\mathrm{kg} / \mathrm{m} 2)\end{array}$} & Mean $\pm \mathrm{SD}$ & $23.5 \pm 1.9$ & $23.3 \pm 1.8$ & \multirow{2}{*}{$\wedge 0.645$} \\
\hline & Range & $18.3-27.8$ & $19.2-27.0$ & \\
\hline \multirow{2}{*}{ Parity } & Mean \pm SD & $2.4 \pm 1.0$ & $2.6 \pm 1.2$ & \multirow{2}{*}{$\wedge 0.309$} \\
\hline & Range & $0.0-4.0$ & $0.0-5.0$ & \\
\hline \multirow{3}{*}{$\begin{array}{l}\text { Indication } \\
(\mathrm{n}, \%)\end{array}$} & Hysterectomy & $43(74.1 \%)$ & $42(72.4 \%)$ & \multirow{3}{*}{$\# 0.962$} \\
\hline & Ovarian cystectomy & $8(13.8 \%)$ & $8(13.8 \%)$ & \\
\hline & Myomectomy & $7(12.1 \%)$ & $8(13.8 \%)$ & \\
\hline
\end{tabular}

${ }^{\wedge}$ Independent t-test, \#Chi square test

Table 2: Pain perception (VAS-100) among the studied groups

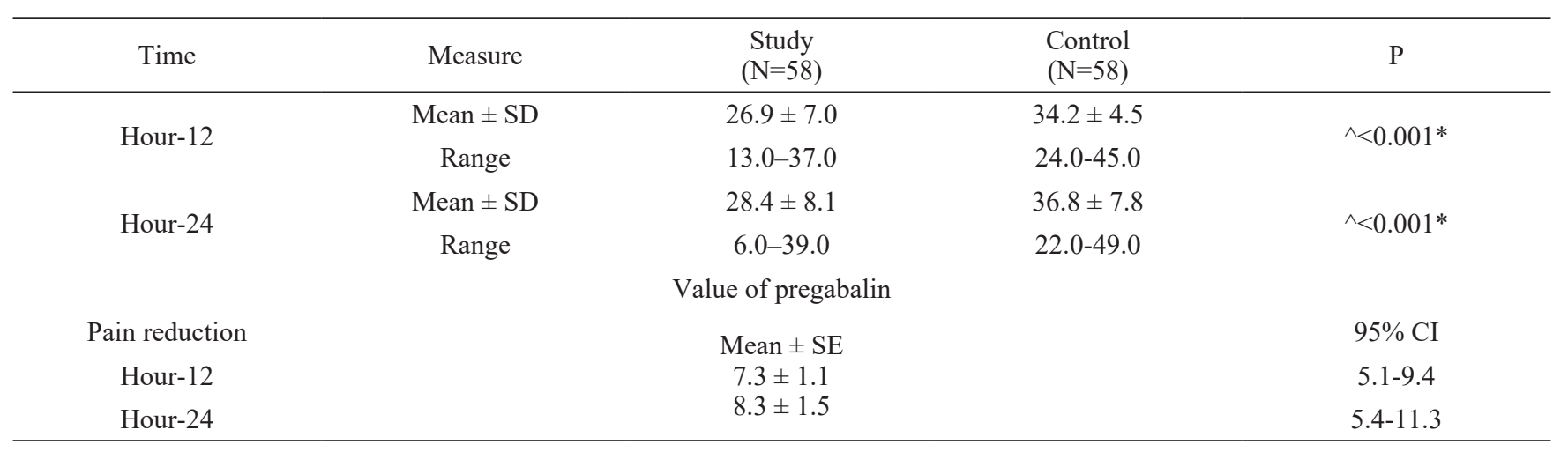

$\wedge$ Independent t-test, CI: Confidence interval, *Highly significant

Table 3: Analgesia-free time (hours) among the studied groups

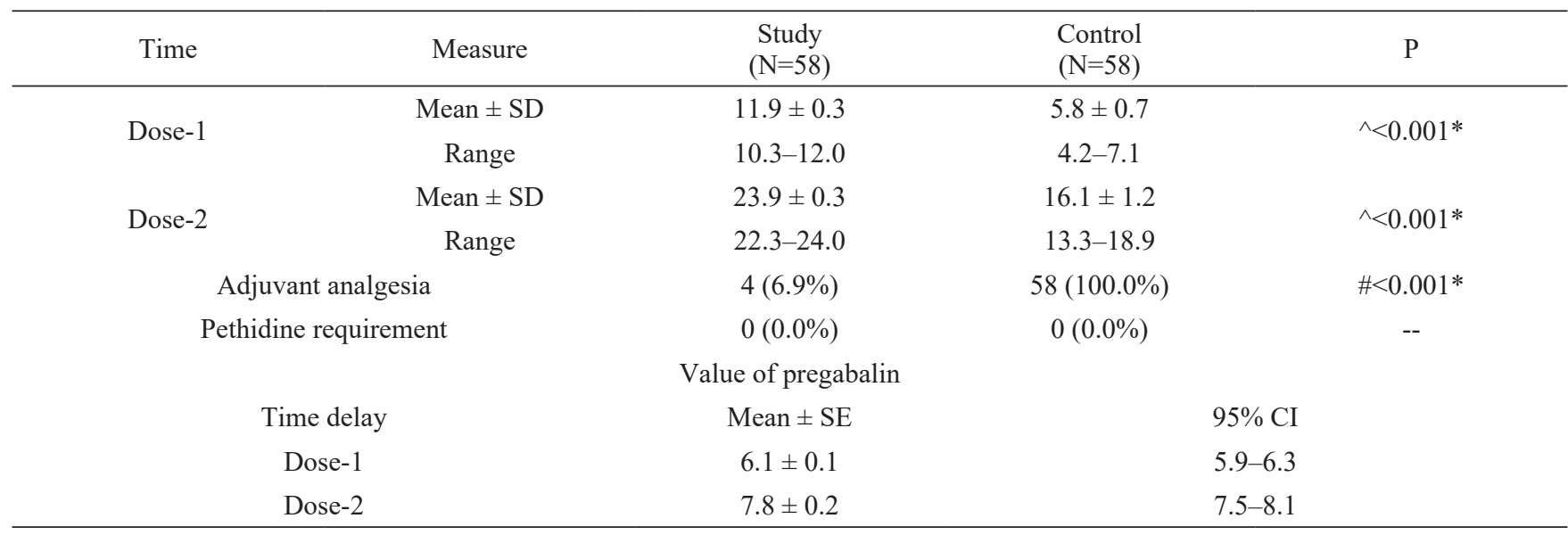

${ }^{\wedge}$ Independent t-test, \# Chi square, CI: Confidence interval, *Highly significant

Table 4 : Locomotor activity start (hours) among the studied groups

\begin{tabular}{ccc}
\hline Measures & $\begin{array}{c}\text { Study } \\
(\mathrm{N}=58)\end{array}$ & $\begin{array}{c}\text { Control } \\
(\mathrm{N}=58)\end{array}$ \\
\hline Mean $\pm \mathrm{SD}$ & $9.1 \pm 0.6$ & $9.9 \pm 0.7$ \\
Range & $8.1-10.6$ & $8.7-11.8$ \\
\hline
\end{tabular}

${ }^{\wedge}$ Independent t-test, CI: Confidence interval, * significant 
Table 5: Intestinal activity among the studied groups

\begin{tabular}{|c|c|c|c|c|}
\hline Items & Measure & $\begin{array}{c}\text { Study } \\
(\mathrm{N}=58)\end{array}$ & $\begin{array}{l}\text { Control } \\
(\mathrm{N}=58)\end{array}$ & $\mathrm{P}$ \\
\hline \multirow{2}{*}{ Intestinal activity (hours) } & Mean \pm SD & $9.4 \pm 1.5$ & $9.7 \pm 1.7$ & \multirow{2}{*}{$\wedge^{\wedge} 0.381$} \\
\hline & Range & $6.4-13.1$ & $6.1-13.0$ & \\
\hline \multicolumn{2}{|c|}{ Intestinal stimulation (glycerin) (n, \%) } & $3(5.2 \%)$ & $4(6.9 \%)$ & $\$ 1.000$ \\
\hline
\end{tabular}

$\wedge^{\wedge}$ Independent t-test, §Fisher's Exact test

Table 6: Side effects among the studied groups

\begin{tabular}{|c|c|c|c|c|}
\hline Items & $\begin{array}{c}\text { Study } \\
(\mathrm{N}=58)\end{array}$ & $\begin{array}{l}\text { Control } \\
(\mathrm{N}=58)\end{array}$ & $\mathrm{P}$ & $\begin{array}{c}\mathrm{RR} \\
(95 \% \mathrm{CI})\end{array}$ \\
\hline Somnolence & $12(20.7 \%)$ & $3(5.2 \%)$ & ${ }^{\wedge} 0.013^{*}$ & $1.76(1.26-2.45)$ \\
\hline Dizziness & $8(13.8 \%)$ & $4(6.9 \%)$ & ${ }^{\wedge} 0.223$ & $1.39(0.89-2.17)$ \\
\hline Headache & $9(15.5 \%)$ & $5(8.6 \%)$ & $\wedge^{\wedge} 0.254$ & $1.34(0.86-2.08)$ \\
\hline Dry mouth & $6(10.3 \%)$ & $3(5.2 \%)$ & $\# 0.490$ & $1.37(0.83-2.26)$ \\
\hline
\end{tabular}

${ }^{\wedge}$ Chi square test, \#Fisher's Exact test, CI: Confidence interval

\section{DISCUSSION}

The current study aimed to assess the efficacy of adding oral pregabalin $150 \mathrm{mg}$ as adjuvant analgesia to i.v diclofenac sodium in comparison to i.v diclofenac sodium to relief pain postoperatively.

A randomized controlled trial was done on female patients that had laparotomies for benign gynaecological diseases in Ain Shams University Maternity Hospital during duration of nine months. The trial included one hundred and sixteen patients, divided into two equal groups. The first group (group A) received oral pregabalin $150 \mathrm{mg}$ one hour before operation and 12 hours after operation and repeated every 12 hours for the first 24 hours and/ or on demand. The second group (group B) received intravenous diclofenac sodium $75 \mathrm{mg} 12$ hours after operation and repeated every 12 hours for the first 24 hours and/or on demand. The degree of pain was assessed 12 hours and 24 hours after surgery using VAS-100 score. Other objective parameters were assessed such as the need for extra doses of opioid from six hours till 24 hours post-operative, early patient ambulation and audible intestinal sounds eight hours till 12 hours postoperative. Finally, the need of intestinal stimulant such as glycerine rectal suppository ( 2 ovules) in case of absence of bowel movement up to twelve hours after surgery was observed.

As regard the demographic data of the studied groups; age, BMI, parity as well as the indications for laparotomy (hysterectomy, myomectomy and ovarian cystectomy), there were no significant differences between the studied groups.
As regard pain perception according to VAS-100 score, it was significantly lower by $20-25$ in the first 12 hours as well as 12-24 hours postoperative among group A.

This study is the first trial that compared oral pregabalin $150 \mathrm{mg}$ added to i.v diclofenac sodium $75 \mathrm{mg}$ in (group A) versus i.v diclofenac sodium $75 \mathrm{mg}$ in (group B) after gynaecological surgeries. Almost all previous studies compared oral pregabalin versus placebo or analgesics.

This study agreed with the study done by Jokela et al. ${ }^{[14]}$ which found a reduced pain score by VAS-100 in female patients following laparoscopic gynecological surgeries that compared preoperative oral pregabalin versus post-operative oral ibuprofen as (COX 1). In addition, our study agreed with that done by Rajappa et al. ${ }^{[15]}$ which found a reduced pain score by VAS-100 in female patients that done hysterectomy and received preoperative oral pregabalin in comparison to placebo.

A group of studies done on patients who underwent hysterectomy like that done by Ittichaikulthol et $a l^{[16]}$, Yücel et $a l^{[17]}$ and Fassoulaki et $a{ }^{[18]}$ as well as many studies done in 2014 like that of Chotton et al. ${ }^{[19]}$, Eman et al. ${ }^{[20]}$ and George et al. ${ }^{[21]}$. All these studies had found a significant post-operative reduction in VAS-100 score in patients who took different dose regimens of oral pregabalin $(75-150 \mathrm{mg}$ ) in comparison with those who took any post-operative NSAID analgesic or placebo, which went in accordance with the current study. 
Another studies done on patients who had myomectomy; Fassoulaki et al. ${ }^{[18]}$ and Bafna et al. ${ }^{[23]}$ had found also a great significant post-operative reduction in VAS-100 score in patients that were given different dose regimens of oral pregabalin (75-150 mg) in comparison with those given any post-operative NSAID analgesic or placebo. These findings went also in accordance with the current study.

Also, studies done on patients who had ovarian cystectomy; Jokela et al. ${ }^{[14]}$, Nutthachote et al. ${ }^{[22]}$ and Singla et al. $^{[24]}$ had found also a great significant postoperative reduction in VAS-100 score in patients that were given different dose regimens of oral pregabalin (75-150 $\mathrm{mg}$ ) in comparison with those given any postoperative NSAID analgesic or placebo. These findings went also in accordance with the current study.

However, our study did not agree with the study done by Paech et al. ${ }^{[25]}$ who found no decrease in VAS-100 score in female patients that had done minor gynecological and received preoperative pregabalin oral when compared to placebo. This difference may be due to being a minor surgery.

The current study revealed that those who took oral pregabalin with i.v. diclofenac sodium $75 \mathrm{mg}$ twelve hours postoperative were significantly free from pain perception when compared to those who took i.v diclofenac sodium $75 \mathrm{mg}$ twelve hours postoperative. In addition, there was significant difference in the second twelve hours between both groups.

As regards the average duration of pain free interval perceived by patients took oral pregabalin, it was found that it was around six hour after the first dose and around eight hours after the second dose. This agreed with the study done by Kohli et al. ${ }^{[26]}$ on those who took preoperative pregabalin orally before hysterectomy as well as that done by Ghai et al. ${ }^{[27]}$ who compared the analgesic effect of preoperative pregabalin orally versus oral gabapentin in abdominal hysterectomy patients.

This study showed also a significant early postoperative mobilisation by one hour in those who took pregabalin orally in comparison with those who took diclofenac sodium i.v., which was attributed to decreased pain perception.

It revealed also no significant difference between both groups regarding the intestinal activity. These findings agree with that of Fassoulaki et al. ${ }^{[18]}$ and Chotton et al. ${ }^{[19]}$.

From this study, we concluded that the importance of administration of oral pregabalin preoperatively was helping early patient mobilization which finally improved the surgical outcome and the patient quality of life.

\section{CONCLUSION}

Administration of oral pregabalin $150 \mathrm{mg}$ preoperatively reduced post-operative pain following abdominal gynecological operations, decreased the need of usage of post-operative narcotic analgesic, helped early patient mobilization and finally improved the surgical outcome and the patient quality of life. We can use oral pregabalin $150 \mathrm{mg}$ as a single dose preoperatively to reduce postoperative pain as it is expensive to use it as a postoperative analgesia by full dose. It is contraindicated to be used in patients complaining of depression, drowsiness and heart failure.

\section{CONFLICT OF INTEREST}

There are no conflicts of interest.

\section{REFERENCES}

1. Sommer M, de Rijke JM, van Kleef $M$, Kessels AG, Peters ML, Geurts JW et al. (2008): The prevalence of postoperative pain in a sample of 1490 surgical inpatients. Eur J Anaesthesiol., 25: 267-274.

2. Bekker A, Haile M, Kline R, Didehvar S et al. (2013): The effect of intraoperative infusion of dexmedetomidine on the quality of recovery after major spinal surgery. $J$ Neurosurg Anesthesiol., 25: 16-24.

3. Cashman JN, Dolin SJ (2004): Respiratory and haemodynamic effects of acute postoperative pain management: evidence from published data. Br J Anaesth., 93 (2): 212-223.

4. Kelhet H, Dahl JB (2003): Anaesthesia, surgery and challenges in post-operative recovery. Lancet, 362 (9399): 1921-1928.

5. Gan TJ (2010): Diclofenac: An update on its mechanism of action and safety profile. Curr Med Res Opin., 26: 1715-1731.

6. Chelly JE, Singla SK, Melson TI, Lacouture PG, Paadre S, Carr DB (2013): Safety of a novel parenteral formulation of diclofenac after major orthopedic or abdominal/ pelvic surgery in a population including anticoagulated, elderly or renally insufficient patients: an open-label, multiday, repeated dose clinical trial. Pain Med., 14 (5): 749-761. 
7. Hospira I (2016): https://www.pfizer.com/sites/ default/files/products/material_safety_data/ Irinotecan_hydrochloride_injection(Hospira)_11Aug-2016.pdf

8. Hindmarch I, Dawson J, Stanley N (2005): A double-blind study in healthy volunteers to assess the effects on sleep of pregabalin compared with alprazolam and placebo. Sleep, 28 (2): 187-193.

9. Clarke H, Page GM, McCartney CJ et al. (2015): Pregabalin reduces postoperative opioid consumption and pain for 1 week after hospital discharge, but does not affect function at 6 weeks or 3 months after total hip arthroplasty. $\mathrm{Br} \mathrm{J}$ Anaesth., 11 (15): 903-911.

10. Cegin MB, Soyoral L, Yuzkat N et al. (2016): Pregabalin administered as an anxiolytic agent in ultrasound-guided infraclavicular block: a controlled, double-blind, dose-ranging trial. Eur Rev Med Pharmacol Sci., 20: 568-574.

11. Mishriky BM, Waldron NH, Habib AS (2015): Impact of pregabalin on acute and persistent postoperative pain: a systematic review and metaanalysis. Br J Anaesth., 31: 110-114.

12. Imani F, Rahimzadeh P (2012): Gabapentinoids: gabapentin and pregabalin for postoperative pain management. Anesth Pain Med., 2 (2): 52-53.

13. Chow S-C, Shao J, Wang H (2003): Sample Size Calculations in Clinical Research. First Edition. New York: Marcel Dekker Inc; ISBN 0824709705.

14. Jokela R, Ahonen J, Tallgren M, Haanpää M, Korttila K (2008): Premedication with pregabalin 75 or $150 \mathrm{mg}$ with ibuprofen to control pain after day-case gynaecological laparoscopic surgery. British Journal of Anaesthesia, 100 (6): 834-840.

15. Rajappa GC, Vig S, Bevanaguddaiah $\mathrm{Y}$, Anadaswamy TC (2016): Efficacy of pregabalin as premedication for post-operative analgesia in vaginal hysterectomy. Anesthesiology and Pain Medicine, 6 (3): e34591.

16. Ittichaikulthol W, Virankabutra $T$, Kunopart M, Khamhom W, Putarawuthichai P, Rungphet S (2009): Effects of pregabalin on post operative morphine consumption and pain after abdominal hysterectomy with/ without salphingooophorectomy: a randomized, double-blind trial. Medical Journal of the Medical Association of Thailand, 92 (10): 1318-1323.
17. Yücel A, Özturk E, Aydoğan MS, Durmuş M, Çolak C, Ersoy MÖ (2011): Effects of 2 different doses of pregabalin on morphine consumption and pain after abdominal hysterectomy: a randomized, double-blind clinical trial. Current Therapeutic Research, 72 (4): 173-183.

18. Fassoulaki A, Melemeni A, Tsaroucha A, Paraskeva A (2012): Perioperative pregabalin for acute and chronic pain after abdominal hysterectomy or myomectomy: a randomised controlled trial. European Journal of Anaesthesiology (EJA), 29 (11): 531-536.

19. Chotton T, Singh N, Singh L et al. (2014): The effect of pregabalin for relief of postoperative pain after abdominal hysterectomy. J Med Soc., 28:18-21.

20. Eman A, Bilir A, Beyaz S (2014): The effects of preoperative pregabalin on postoperative analgesia and morphine consumption after abdominal hysterectomy. Acta Medica Meditrranea., 30: 481-485.

21. George RB, McKeen DM, Andreou P, Habib AS (2014): A randomized placebo-controlled trial of two doses of pregabalin for postoperative analgesia in patients undergoing abdominal hysterectomy. Canadian Journal of Anesthesia/Journal Canadien D'anesthésie, 61 (6): 551-557.

22. NutthachoteP, SirayapiwatP, Wisawasukmongchol W, Charuluxananan S (2014): A randomized, double-blind, placebo-controlled trial of oral pregabalin for relief of shoulder pain after laparoscopic gynecologic surgery. Journal of Minimally Invasive Gynecology, 21 (4): 669-673.

23. Bafna U, Rajarajeshwaran $\mathrm{K}$, Khandelwal $\mathrm{M}$ et al. (2014): A comparison of effect of preemptive use of oral gabapentin and pregabalin for acute post-operative pain after surgery under spinal anesthesia. J Anaesth Clin Pharm., 30: 373-377.

24. Singla NK, Chelly JE, Lionberger DR et al. (2015): Pregabalin for the treatment of postoperative pain: results from three controlled trials using different surgical models. J Pain Res., 8: 12-15.

25. Paech MJ, Goy R, Chua S, Scott K, Christmas T, Doherty DA (2007): A randomized placebo- controlled trial of preoperative oral pregabalin for post-operative pain relief after minor gynaecological surgery. Anaesth Analg., 105: 1449-1453. 
26. Kohli M, Murali T, Gupta R, Khan P, Bogra J (2011): Optimization of subarachanoid block by oral pregabalin for hysterectomy. Journal of Anaesthesiology, Clinical Pharmacology, 27(1): 101-105.
27. Ghai A, Gupta M, Hooda S, Singla D, Wadhera R (2011): A randomized controlled trial to compare pregabalin with gabapentin for postoperative pain in abdominal hysterectomy. Saudi J Anaesth., 5 (3): 252-257. 